\title{
Evaluating the clinical and economic burden of healthcare-associated infections during hospitalization for surgery in France
}

\author{
L. LAMARSALLE ${ }^{1 *}$, B. HUNT ${ }^{2}$, M. SCHAUF ${ }^{3}$, K. SZWARCENSZTEIN ${ }^{4}$ \\ AND W.J. VALENTINE ${ }^{2}$ \\ ${ }^{1}$ HEVA-Health Evaluation, Lyon, France \\ ${ }^{2}$ Ossian Health Economics and Communications, Basel, Switzerland \\ ${ }^{3}$ Johnson and Johnson, Hamburg, Germany \\ ${ }^{4}$ Johnson and Johnson, Issy-les-Moulineaux, France
}

Received 20 September 2012; Final revision 22 January 2013; Accepted 22 January 2013; first published online 28 February 2013

\section{SUMMARY}

Over 4 million patients suffer nosocomial infections annually in the European Union. This study aimed to estimate the healthcare burden associated with healthcare-associated infections (HAIs) following surgery in France, and explore the potential impact of infection control strategies and interventions on the clinical and economic burden of disease. Data on the frequency of HAIs were gathered from the 2010 Programme de Médicalisation des Systèmes d'Information (PMSI), and cost data were taken from the 2009 Echelle Nationale de Coûts à Méthodologie Commune (ENCC). It was estimated that 3\% of surgical procedures performed in 2010 in France resulted in infection, resulting in an annual cost of $€ 57892715$. Patients experiencing a HAI had a significantly increased mortality risk (4-15-fold) and an increased length of hospital stay (threefold). Scenario analysis in which HAI incidence following surgery was reduced by $8 \%$ (based on a study of the effectiveness of triclosan-coated sutures), suggested that, annually, 20205 hospital days and $€ 4588519$ could be saved. Analyses of $20 \%$ and $30 \%$ reductions in incidence (based on an estimate of the number of preventable nosocomial infections) suggested that annual savings of $€ 11548057$ and $€ 17334696$, respectively, could be made. New infection control interventions which reduce HAI incidence during hospitalization for surgery have the potential to provide valuable cost savings to healthcare providers.

Key words: Cost, France, healthcare-associated infections, nosocomial infections, surgical site infections.

\section{INTRODUCTION}

Annually, over 4 million patients within the 27 European Union member states acquire a nosocomial infection, of whom approximately 37000 will die as a result [1]. Surgical site infections (SSIs) are the third most common form of healthcare-associated infection

\footnotetext{
* Author for correspondence: Dr L. Lamarsalle, Immeuble 6ème sens, 186 Avenue Thiers, 69465 Lyon, Cédex 06, France. (Email: 1lamarsalle@hevaweb.com)
}

(HAI), behind urinary tract $(27 \%)$ and lower respiratory tract $(24 \%)$ infections, comprising $17 \%$ of cases [1]. The economic impact of SSIs is considerable, with an estimated burden on European healthcare providers of $€ 7$ billion in 2008 [2]. Costs are driven predominantly by increased length of hospital stay, estimated to be an average 9.8-day increase compared to patients not experiencing a SSI [3].

In France, surveillance of HAIs has been in place since the early 1990s. It has been estimated that the crude incidence of SSIs in France, between 1996 and 
2006, was $1 \cdot 54 \%$ in patients undergoing either elective or emergency surgery [4]. The incidence varied depending on the surgical intervention, from $0.49 \%$ for knee prosthesis to $9 \cdot 24 \%$ for colon surgery [5]. Despite an increase in the number of patients undergoing surgical procedures, in particular patients deemed to be at high risk of SSI, such as elderly patients, analysis of temporal trends has shown that the incidence of nosocomial infections in France has decreased in recent years [5-7]. The reduction in SSI incidence has been attributed, in part, to the successful introduction of active surveillance programmes such as the Infection du site Opératoire-Réseau Alerte Investigation Surveillance des Infections (ISO-RAISIN) and Incidence des Infections du Site Opératoire (INCISO), and the utilization of infection control strategies that have accompanied surveillance $[4,8]$. The majority of SSIs are preventable; with a recent USA-based study finding that up to $55 \%$ of cases could be avoided [9].

ISO-RAISIN data from 2007 showed that the most common infectious causative agents of SSIs were Escherichia coli (25\%), Staphylococcus aureus (19\%) and Pseudomonas aeruginosa (10\%) [10]. Of the identified strains, $10 \%$ of $E$. coli isolates were cefotaximeor ceftriaxone-resistant, $19 \%$ of $S$. aureus were methicillin-resistant and $25 \%$ of $P$. aeruginosa were ceftazidime-resistant. The frequency of infection by resistant strains of bacteria significantly adds to the burden of SSIs as more expensive second-line treatments become necessary.

Published data describing the total economic burden of nosocomial infections and SSIs in France are currently lacking. A recent single-centre study found that the mean additional cost per patient experiencing a SSI, taking into account laboratory tests, radiology, surgery, exploratory examinations and antimicrobial agents, was $€ 1814$ [11]. The aim of the present study was to estimate the healthcare burden associated with SSIs, both nationally and by region, in France and to explore the potential impact of infection control strategies on the overall clinical and economic burden.

\section{METHODS}

\section{Identification of surgical procedures and incidence of HAI}

The frequency of 12 preselected surgical procedure categories (Table 1) performed in France between
Table 1. Daily cost of hospital care following healthcare-associated infection by surgical procedure, in public and private hospitals

\begin{tabular}{|c|c|c|}
\hline Surgical procedure & $\begin{array}{l}\text { Daily cost of } \\
\text { care in public } \\
\text { hospitals }(€)\end{array}$ & $\begin{array}{l}\text { Daily cost of } \\
\text { care in private } \\
\text { hospitals }(€)\end{array}$ \\
\hline Amputation & 276 & 171 \\
\hline $\begin{array}{l}\text { Coronary artery } \\
\text { bypass }\end{array}$ & 268 & 163 \\
\hline $\begin{array}{l}\text { Thoracic or } \\
\text { abdominal artery } \\
\text { surgery }\end{array}$ & 219 & 131 \\
\hline $\begin{array}{l}\text { Thoracic or } \\
\text { abdominal vein } \\
\text { surgery }\end{array}$ & 261 & - \\
\hline $\begin{array}{l}\text { Kidney or pelvic } \\
\text { surgery }\end{array}$ & 259 & 162 \\
\hline Caesarean & 281 & 160 \\
\hline $\begin{array}{l}\text { Colon and rectal } \\
\text { surgery }\end{array}$ & 240 & 162 \\
\hline Bowel surgery & 304 & 177 \\
\hline $\begin{array}{l}\text { Laparoscopic } \\
\text { hysterectomy }\end{array}$ & 293 & 189 \\
\hline $\begin{array}{l}\text { Intracranial or } \\
\text { cerebrospinal fluid } \\
\text { surgery }\end{array}$ & 263 & 171 \\
\hline Prostate surgery & 166 & 150 \\
\hline Organ transplant & 290 & 172 \\
\hline
\end{tabular}

$€=2009$ euros.

1 January 2010 and 31 December 2010 was quantified through searching of the Programme de Médicalisation des Systèmes d'Information (PMSI) using 507 appropriate Classification Commune des Actes Medicaux (CCAM) procedure codes, selected from about 8000 codes used to index hospital procedures in France. The 12 procedure categories were chosen to provide an overview of SSIs in France, but do not encompass all surgical procedures performed in 2010, and therefore the total incidence is underestimated. PMSI is a comprehensive database of hospital visits in France since all hospitals, both public and private, are legally obliged to report activity for collation, otherwise remuneration for the procedure performed is withheld by the local health authority $[12,13]$. It is recommended as an epidemiological tool by the French guidelines for health economic evaluation [14]. As well as detailing the procedure performed using CCAM codes, the database contains details of length of hospital stay, patients' details (such as age) and an anonymous patient identifier to allow future hospitalizations to be followed. 
Having identified patients undergoing surgical procedures in France, the incidence of SSIs was examined by inspection of patients' history subsequent to surgery for the Classification Statistique Internationale des Maladies et des Problèmes de Santé Connexes (ICD-10) codes relating to infection, namely T814 (Infection following a therapeutic or diagnostic procedure, not classified elsewhere), L02 (Cutaneous abscess, furuncle, carbuncle), and Y95 (Nosocomial infection). Since these codes are not specific to infection of the surgical site, data shown is for HAI incidence following surgery.

\section{Estimation of daily cost of care}

Daily costs of care were calculated for both public and private hospitals based on resource use and cost data from the 2009 Echelle Nationale de Coûts à Méthodologie Commune (ENCC). The ENCC provides costs of care, taking into account costs of a range of factors, including medical professionals, drug costs, and running costs of the medical unit (e.g. cleaning and laundry). It is possible to evaluate daily physician costs for public hospitals, but this is not the case for private hospitals since physicians are reimbursed per CCAM procedure performed rather than per day of care administered, and therefore physician costs are captured in public, but not private, hospitals. In this analysis only costs allocated to the days of stay following surgical procedures were included. The mean daily cost of care, in 2009 euros $(€)$, following each category of surgical procedure is summarized in Table 1 .

\section{Health economic model}

Having collected data on the length of stay in patients with and without HAI, a health economic model was constructed to evaluate cost differences between the infection control scenarios. A bespoke model was coded, with SQLite and Adobe Air used to manage the database and present the results. A 1-year time horizon was used with outcomes evaluated from a hospital perspective. In this model HAI incidence could be varied to examine the clinical and economic impact of infection control interventions used. Model inputs were length of stay associated with each procedure with and without HAI, daily cost of hospital care following each procedure, and HAI incidence following each procedure. The model reported outputs of number of hospital stays, number of hospital days of care, and cost of care.
Table 2. Summary of episodes of hospital care included in the analysis (with and without HAI)

\begin{tabular}{|c|c|c|c|}
\hline & $\begin{array}{l}\text { Without } \\
\text { HAI }\end{array}$ & $\begin{array}{l}\text { With } \\
\text { HAI }\end{array}$ & Total \\
\hline Number of procedures & 505195 & 15520 & 520715 \\
\hline $\begin{array}{l}\text { Median length of stay } \\
\text { (days) }\end{array}$ & 7 & 22 & 7 \\
\hline Number of deaths & 10326 & 1293 & 11619 \\
\hline
\end{tabular}

HAI, healthcare-associated infection.

As well as examining the burden at current rates of infection, three scenario analyses were performed in which HAI incidence was varied. In the first scenario HAI incidence was reduced by $8 \%$. This was based on a recent study of the use of triclosan antibacterial sutures, which found that SSI incidence was reduced by $8 \%(7 \%$ vs. $15 \%)$ compared to the control arm in which conventional sutures were used [15]. To examine the impact of less focused approaches that could be used to reduce SSIs, scenarios with $20 \%$ and $30 \%$ reduction in incidence were also analysed. These were based on the upper and lower limits of an estimate of the number of preventable nosocomial infections, made by the European Centre for Disease Prevention and Control [1].

\section{Statistical analysis}

Descriptive statistics were used to summarize the clinical and economic data from the analysis. Statistical analysis was conducted to examine differences between clinical outcomes in patients experiencing HAI and those not experiencing HAI, based on the data collected from PMSI. Hypothesis testing of the difference between normally distributed variables was performed using $\chi^{2}$ tests, while Mann-Whitney $U$ tests were used for non-normally distributed variables. Normality tests, to determine whether the data were well modelled by a normal distribution, were performed using Kolmogorov-Smirnov nonparametric tests.

\section{RESULTS}

\section{Incidence of SSI}

The PMSI data showed that of 520715 selected surgical procedures performed between 1 January 2010 and 31 December 2010, 3.0\% resulted in infection (Table 2). Frequency of HAI was correlated with 


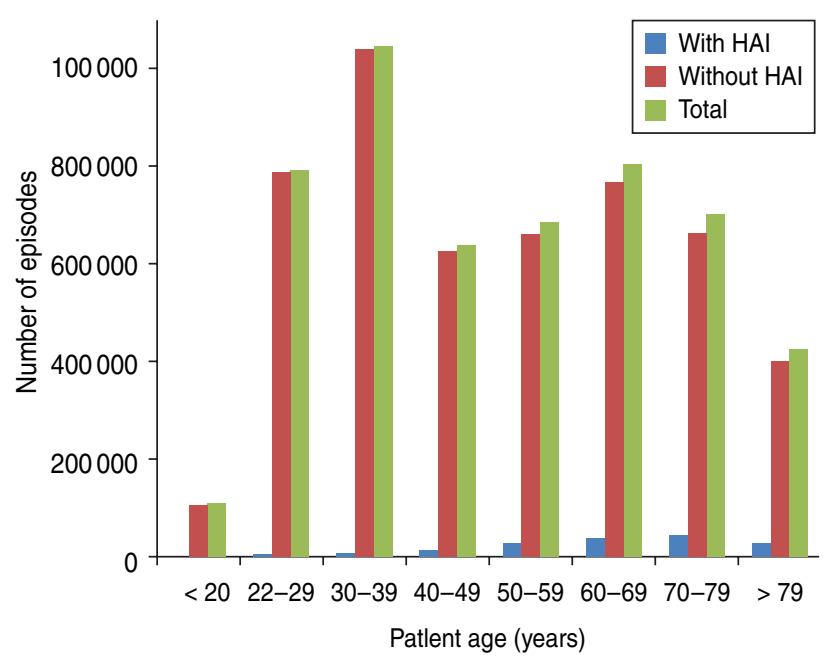

Fig. 1. Distribution of hospital stays by age. HAI, Healthcare-associated infection.

age, with $43.9 \%$ of cases occurring in patients aged $\geqslant 70$ years, while only $15 \cdot 1 \%$ of cases involved patients aged $<50$ years (Fig. 1). The frequency of HAI also varied with the type of surgery performed (Table 3). Of the selected surgical procedures, the group with the highest incidence of HAI was organ transplant, with $13 \cdot 1 \%$ of surgeries resulting in HAI. Caesarean section had the lowest incidence of HAI, with only $0 \cdot 1 \%$ of procedures being followed by infection. The clinical burden of HAI was greatest following colon and bowel surgery, comprising $49 \cdot 1 \%$ and $22.0 \%$, respectively, of the total HAI cases. Incidence also varied by region (Fig. 2). It was found that the highest incidence of infection was in Martinique $(5 \cdot 1 \%)$ and the lowest in French Guiana $(0 \cdot 7 \%)$. Of the mainland French regions, the highest incidence was found in Languedoc-Roussillon (4-2\%) and the lowest incidence in Alsace $(2 \cdot 2 \%)$. However, when corrected for case mix it was found that incidence rates were similar across regions. This suggests that differences found between regions were due to the number of high-risk procedures performed, rather than other factors influencing HAI incidence. The incidence rates in public and private hospitals showed minimal variation, with $2 \cdot 9 \%$ and $3 \cdot 1 \%$ of procedures resulting in HAI, respectively. Incidence rates by procedure were also found to be comparable for public and private hospitals.

\section{Clinical burden of SSI}

HAI was associated with a statistically significant increase in mortality. The mortality rate in patients experiencing a HAI was $8 \cdot 3 \%$, compared to $2 \cdot 0 \%$ in patients who did not $(P<0 \cdot 001)$, corresponding to a $4 \cdot 15$-fold relative increase (Table 3 ). The largest increase in mortality rate was seen in the thoracic or abdominal vein and thoracic or abdominal artery surgery groups, where mortality rates increased over 50-fold, from $0 \cdot 2 \%$ to $10 \cdot 4 \%$, and $2 \cdot 3$-fold, from $6 \cdot 3 \%$ to $14 \cdot 3 \%$, respectively. Mortality rates did not vary in public and private hospitals. Length of hospital stay was found to be non-normally distributed (Kolmogorov-Smirnov $D=0 \cdot 253, P<0 \cdot 01$ ). Patients experiencing HAI had a threefold longer hospital stay than those who did not, with median length of stay increasing from 7 days to 22 days $(P<0 \cdot 001)$. When mean length of hospital stay following each procedure was evaluated, it was found that HAI was associated with at least a twofold longer stay following all procedures (Table 3). Of particular note was the almost tenfold increase following thoracic or abdominal vein surgery, with mean length of stay increasing from 3 days to 29 days following the procedure if HAI occurred.

\section{Cost of SSI}

The health economic modelling analysis suggested that in 2010, HAIs led to an additional cost to public and private hospitals of $€ 43019936$ and $€ 14872779$, respectively (Table 4). This difference was driven not by the rate of infection, since incidence rates were found to be comparable, but by the increased number of procedures performed in public hospitals and the increased daily cost of care. A total of 86861 more procedures were performed in public hospitals, resulting in 1856 further HAIs. The daily cost of care was 
Table 3. Burden of HAI by procedure

\begin{tabular}{|c|c|c|c|c|c|c|c|}
\hline Surgical procedure & $\begin{array}{l}\text { Number of } \\
\text { procedures } \\
\text { performed }\end{array}$ & $\begin{array}{l}\text { Procedures } \\
\text { resulting in } \\
\text { HAI }(\%)\end{array}$ & $\begin{array}{l}\text { Contribution } \\
\text { to the total } \\
\text { burden of } \\
\text { HAI following } \\
\text { surgery }(\%)\end{array}$ & $\begin{array}{l}\text { Mean length } \\
\text { of stay } \\
\text { without } \\
\text { HAI } \\
\text { (days) }\end{array}$ & $\begin{array}{l}\text { Mean } \\
\text { length of } \\
\text { stay with } \\
\text { HAI } \\
\text { (days) }\end{array}$ & $\begin{array}{l}\text { Mortality } \\
\text { rate without } \\
\text { HAI }(\%)\end{array}$ & $\begin{array}{l}\text { Mortality } \\
\text { rate with } \\
\text { HAI }(\%)\end{array}$ \\
\hline Amputation & 24759 & $5 \cdot 4$ & $8 \cdot 6$ & 17 & 35 & $5 \cdot 7$ & $9 \cdot 8$ \\
\hline $\begin{array}{l}\text { Coronary artery } \\
\text { bypass }\end{array}$ & 18541 & $3 \cdot 5$ & $4 \cdot 1$ & 14 & 31 & $3 \cdot 6$ & $9 \cdot 5$ \\
\hline $\begin{array}{l}\text { Thoracic or } \\
\text { abdominal } \\
\text { artery surgery }\end{array}$ & 30145 & $4 \cdot 1$ & $7 \cdot 9$ & 13 & 35 & $6 \cdot 3$ & $14 \cdot 3$ \\
\hline $\begin{array}{l}\text { Thoracic or } \\
\text { abdominal } \\
\text { vein surgery }\end{array}$ & 35978 & $0 \cdot 3$ & $0 \cdot 7$ & 3 & 29 & $0 \cdot 2$ & $10 \cdot 4$ \\
\hline $\begin{array}{l}\text { Kidney or pelvic } \\
\text { surgery }\end{array}$ & 20619 & $3 \cdot 0$ & $4 \cdot 0$ & 11 & 24 & $1 \cdot 3$ & $6 \cdot 9$ \\
\hline Caesarean & 170349 & $0 \cdot 1$ & $1 \cdot 5$ & 7 & 13 & $0 \cdot 0$ & $0 \cdot 4$ \\
\hline $\begin{array}{l}\text { Colon and rectal } \\
\text { surgery }\end{array}$ & 93430 & $8 \cdot 2$ & $49 \cdot 1$ & 14 & 29 & $4 \cdot 5$ & $8 \cdot 1$ \\
\hline Bowel surgery & 31533 & $10 \cdot 8$ & $22 \cdot 0$ & 17 & 37 & $8 \cdot 5$ & $12 \cdot 4$ \\
\hline $\begin{array}{l}\text { Laparoscopic } \\
\text { hysterectomy }\end{array}$ & 69271 & $1 \cdot 0$ & $4 \cdot 3$ & 6 & 19 & $0 \cdot 2$ & $3 \cdot 0$ \\
\hline $\begin{array}{l}\text { Intracranial or } \\
\text { cerebrospinal } \\
\text { fluid surgery }\end{array}$ & 6465 & $6 \cdot 5$ & $2 \cdot 7$ & 22 & 50 & $13 \cdot 1$ & $16 \cdot 0$ \\
\hline Prostate surgery & 32865 & $3 \cdot 3$ & $6 \cdot 9$ & 9 & 20 & $0 \cdot 3$ & $2 \cdot 3$ \\
\hline Organ transplant & 1742 & $13 \cdot 1$ & $1 \cdot 5$ & 42 & 62 & $12 \cdot 0$ & $12 \cdot 7$ \\
\hline Total & 520715 & $3 \cdot 0$ & 100 & 14 & 32 & $2 \cdot 0$ & $8 \cdot 3$ \\
\hline
\end{tabular}

HAI, Healthcare-associated infection.

Some procedures were classified as more than one type of surgery. Therefore the total number of procedures is not the sum of the individual procedures.

found to be significantly higher in public hospitals for all procedures, ranging from $€ 122$ per day increase for care following intracranial surgery ( $€ 293 v s . € 171)$ to $€ 88$ per day increase following thoracic and abdominal artery surgery (€219 vs. €131). This was, at least in part, driven by the exclusion of physicians' costs in the private sector.

The largest cost burden was that of HAI following kidney or pelvic surgery, costing public hospitals $€ 16195572$ per year and private hospitals $€ 6735474$ per year. An increased number of patients experienced HAI in public hospitals, despite similar rates of infection $(\sim 3 \%$ in both), due to the increased number of procedures performed in public hospitals (12365 in public hospitals vs. 8283 in private hospitals). Furthermore, daily costs of care following kidney or pelvic surgery were $€ 99$ higher in public hospitals than in private hospitals. Expenditure following kidney or pelvic surgery equated to $38 \%$ and $45 \%$, in public and private hospitals, respectively, of additional expenditure as a result of HAI. HAIs had a particularly large cost burden following caesarean
(€13134821), amputation ( $€ 5055414)$ and coronary artery surgery (€4910239), comprising $40 \%$ of additional expenditure, across public and private hospitals, between these three procedures.

\section{Exploratory infection control scenarios}

An $8 \%$ reduction in HAI incidence, based on a recent study into the reduction in SSIs associated with the use of triclosan antibacterial sutures [15] was predicted to result in a saving of 20205 hospital days per year, across both public and private hospitals, resulting in annual cost savings of $€ 3406520$ in public hospitals and $€ 1178999$ in private hospitals. The bulk of the cost savings came from reduced cost of HAI following kidney or pelvic surgery, with public hospitals saving $€ 1294299$ per year and private hospitals saving $€ 537516$ per year, $40 \%$ of total savings (Figs 3, 4).

The analysis in which a $20 \%$ reduction in HAI incidence was applied, based on the lower limit of an estimate of the number of preventable nosocomial infections by the European Centre for Disease 


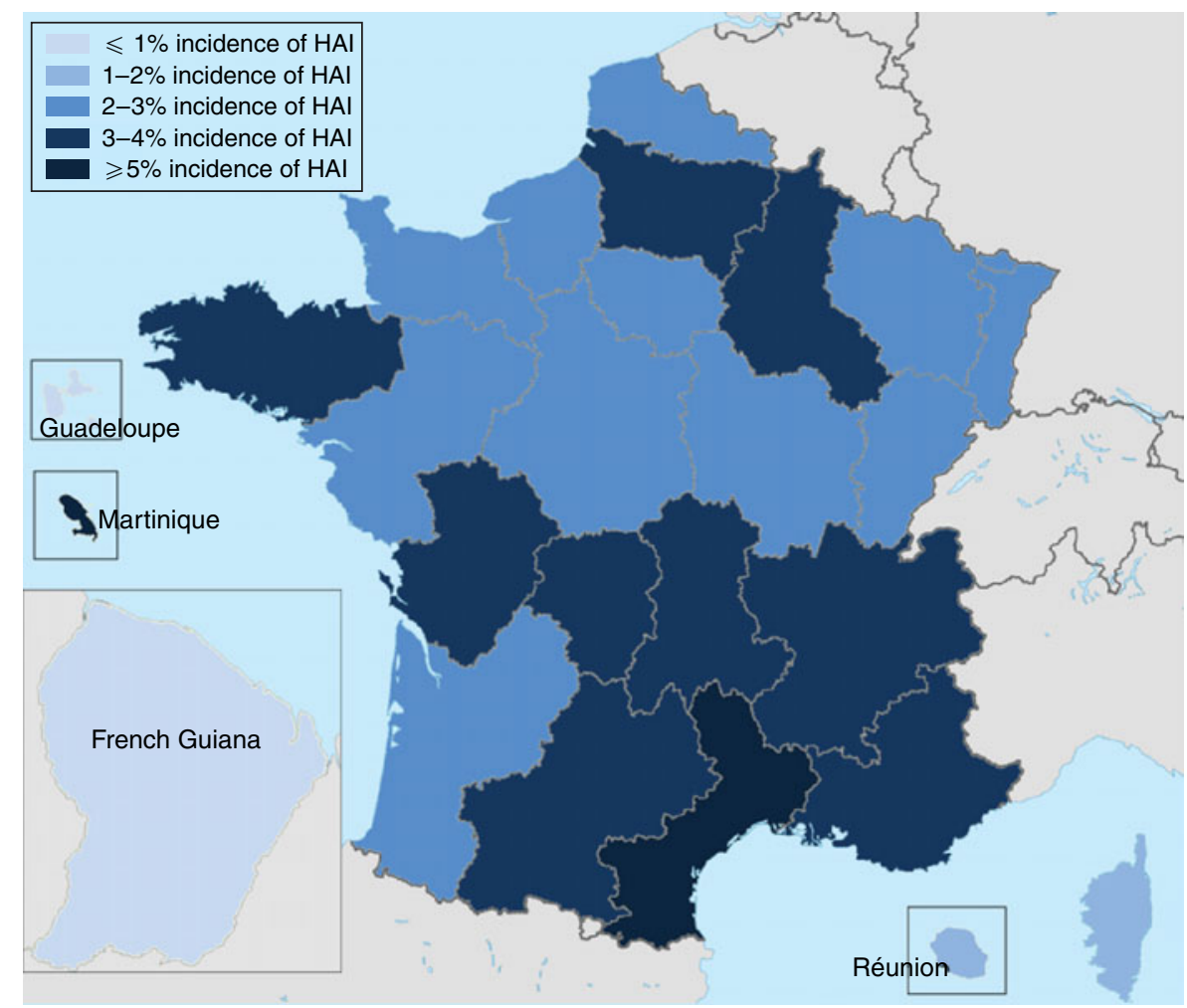

Fig. 2. Incidence of healthcare-associated infection (HAI) following surgery in the 27 regions of France.

Prevention and Control [1] suggested that 3185 HAI cases could be avoided annually, resulting in 50871 hospital days saved. This was made up of 32758 days in public hospitals and 18113 days in private hospitals. Cost savings of $€ 8583202$ per year and $€ 2964855$ per year could be made in public and private hospitals, respectively (Figs 3, 4). Healthcare spending as a result of HAIs was reduced from $€ 57892715$ to $€ 46344658$.

When a $30 \%$ reduction in HAI incidence was applied, based on the upper limit of a European Centre for Disease Prevention and Control estimate of the proportion of nosocomial infections that could be prevented [1], analysis suggested that 76373 hospital days per year could be saved as a result of 4781 HAI cases being avoided. Cost savings of $€ 12880036$ per year could be made in public hospitals, and $€ 4454660$ per year in private hospitals (Figs 3, 4). This saving of $€ 17334696$ represents a $30 \%$ reduction in healthcare spending as a result of HAIs.

\section{DISCUSSION}

The present study has quantified part of the considerable clinical and economic burden of SSIs on the French healthcare system, where about $3 \%$ of the included surgical procedures resulted in infection. The incidence of HAI following surgery increased with patients' age and varied depending on the surgical procedure performed. Included HAIs led to a $4 \cdot 15$-fold increase in post-surgery mortality, a threefold increase in length of hospital stay and an annual cost burden of $€ 57892715$. The largest costs were seen in patients experiencing HAI after kidney or pelvic surgery. The current analysis underestimates the total burden of SSIs on the French health economy for two reasons. First, only a predefined set of surgical procedures were included in the analysis, not all the surgical procedures performed in France in 2010. Furthermore, the ICD-10 codes used captured only infections reported during the initial hospital stay. Since not all SSI cases were identified in this analysis, the clinical and economic estimates are conservative and the burden to the French health economy is expected to be greater. Scenario analysis suggests that reduction in HAI incidence by $8 \%, 20 \%$ and $30 \%$ will result in savings of $€ 4588519, € 11548057$ and $€ 17334696$, respectively. These are substantial cost savings, made predominantly in public hospitals due to the increased number of surgical procedures performed and the increased daily cost of care. The frequency of surgical procedures involving patients 
Table 4. Additional length of hospital stay and additional costs associated with healthcare-associated infection following surgery for public and private hospitals in France

\begin{tabular}{|c|c|c|c|c|c|c|}
\hline \multirow[b]{2}{*}{$\begin{array}{l}\text { Surgical } \\
\text { procedure }\end{array}$} & \multicolumn{3}{|c|}{ Public hospitals } & \multicolumn{3}{|c|}{ Private hospitals } \\
\hline & $\begin{array}{l}\text { Additional } \\
\text { length of } \\
\text { hospital stay } \\
\text { (days) }\end{array}$ & $\begin{array}{l}\text { Additional } \\
\operatorname{cost}(€)\end{array}$ & $\begin{array}{l}\text { Additional cost } \\
\text { per procedure } \\
\text { resulting in HAI } \\
(€)\end{array}$ & $\begin{array}{l}\text { Additional } \\
\text { length of } \\
\text { hospital stay } \\
\text { (days) }\end{array}$ & $\begin{array}{l}\text { Additional } \\
\operatorname{cost}(€)\end{array}$ & $\begin{array}{l}\text { Additional cost } \\
\text { per procedure } \\
\text { resulting in HAI } \\
(€)\end{array}$ \\
\hline Amputation & 14095 & 3890220 & 4968 & 6814 & 1165194 & 3078 \\
\hline $\begin{array}{l}\text { Coronary artery } \\
\text { bypass }\end{array}$ & 13166 & 3528488 & 4556 & 8477 & 1381751 & 2771 \\
\hline $\begin{array}{l}\text { Thoracic or } \\
\text { abdominal artery } \\
\text { surgery }\end{array}$ & 905 & 198195 & 4818 & 292 & 38252 & 2882 \\
\hline $\begin{array}{l}\text { Thoracic or } \\
\text { abdominal vein } \\
\text { surgery }\end{array}$ & 3297 & 547302 & 4316 & - & - & - \\
\hline $\begin{array}{l}\text { Kidney or pelvic } \\
\text { surgery }\end{array}$ & 62052 & 16195572 & 3654 & 41577 & 6735474 & 2268 \\
\hline Caesarean & 40439 & 10473701 & 1554 & 16632 & 2661120 & 960 \\
\hline $\begin{array}{l}\text { Colon and rectal } \\
\text { surgery }\end{array}$ & 4851 & 1363131 & 4215 & 2319 & 375678 & 2430 \\
\hline Bowel surgery & 9010 & 2162400 & 4800 & 594 & 105138 & 3540 \\
\hline $\begin{array}{l}\text { Laparoscopic } \\
\text { hysterectomy }\end{array}$ & 4808 & 1461632 & 3952 & 3096 & 585144 & 2457 \\
\hline $\begin{array}{l}\text { Intracranial or } \\
\text { cerebrospinal } \\
\text { fluid surgery }\end{array}$ & 3478 & 1019054 & 8497 & 7334 & 1254114 & 4959 \\
\hline Prostate surgery & 6347 & 1669261 & 2893 & 3133 & 469950 & 1650 \\
\hline Organ transplant & 1762 & 510980 & 5800 & 587 & 100964 & 3440 \\
\hline Total & 164210 & 43019936 & - & 90855 & 14872779 & - \\
\hline
\end{tabular}

HAI, Healthcare-associated infection.

$€=2009$ euros.

at high risk of SSI is increasing, and therefore the use of infection control strategies is likely to become increasingly important in the future.

One of the major strengths of the present study is the robust epidemiological data on which the health economic model is based. PMSI provides a detailed account of hospital stays and allows the number of procedures and treatments performed in a given timeframe to be accurately determined. Furthermore, the age of the patient and the post-operative clinical consequences can be accurately assessed using the anonymous patient identifier. In this analysis, 507 CCAM codes relating to preselected surgical procedures were used to identify treatments of interest, giving a comprehensive list of procedures performed, while the use of ICD-10 codes relating to HAI allows accurate quantification of HAI incidence following surgery during the initial hospital stay. The bespoke health economic model developed for this analysis, based on these data, may be a valuable tool for future economic evaluations of infection control strategies and interventions in the French setting.

An assumption of this analysis is that the daily cost of care following surgical procedures is the same in patients experiencing HAI and those not experiencing HAI. It may be the case that patients with HAI would require not only a longer period of care, taken into account through the increased length of hospital stay, but also require more intense and expensive care during hospitalization. This may be through increased volume of diagnostic tests to identify the causative pathogen, intensified antimicrobial treatments (including more expensive second-line therapy if the causative agent is resistant to first-line treatments), and increased nursing staff time. Given this conservative assumption, cost savings reducing SSI incidence may be greater than those suggested in this analysis. 


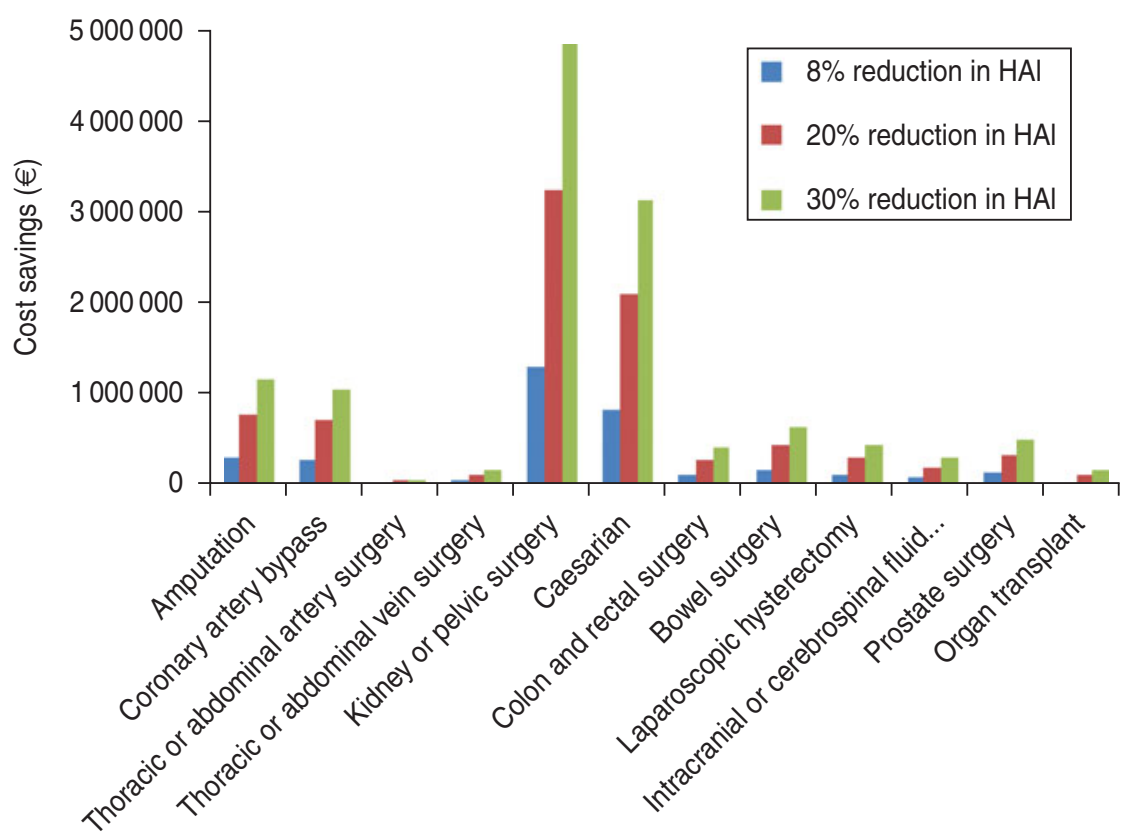

Fig. 3. Cost saving by reducing the incidence of healthcare-associated infections (HAIs) following surgery by $8 \%, 20 \%$ and $30 \%$ in public hospitals. $€=2009$ euros.

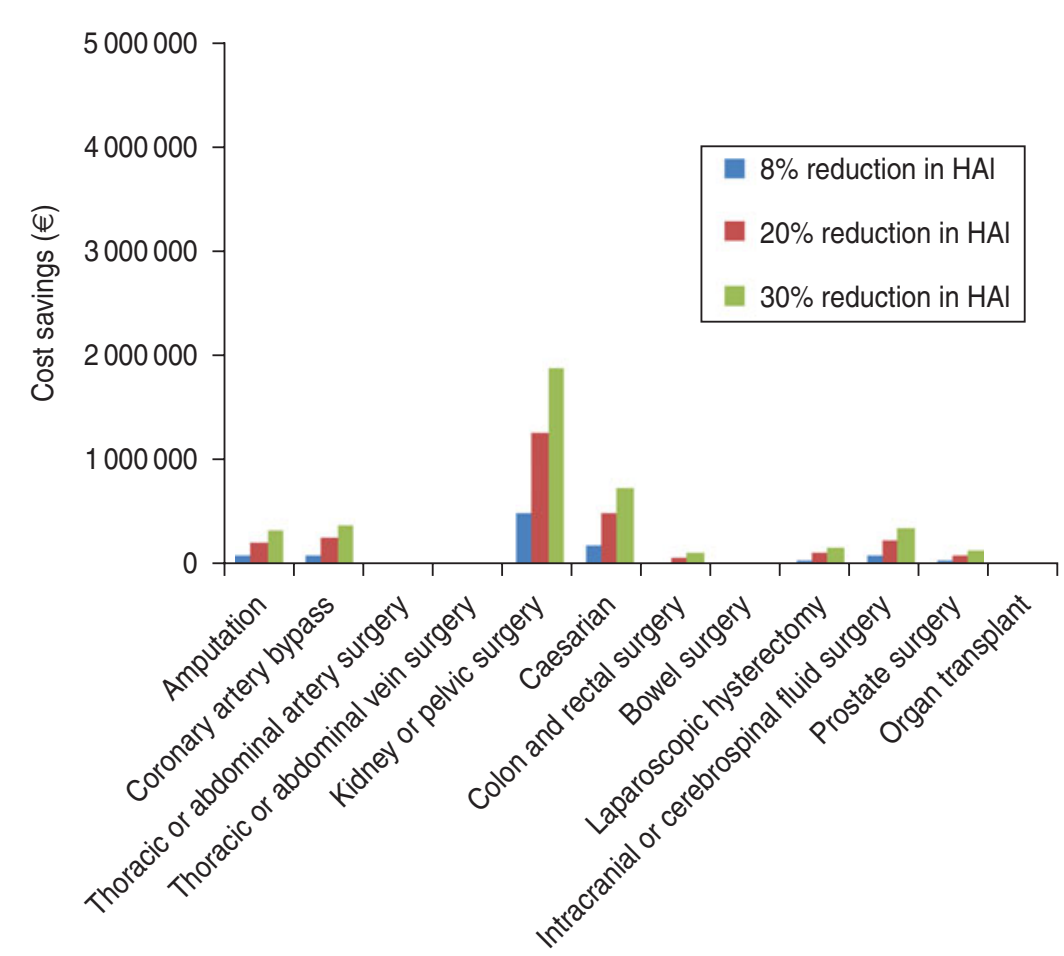

Fig. 4. Cost saving by reducing the incidence of healthcare-associated infections (HAIs) following surgery by $8 \%, 20 \%$ and $30 \%$ in private hospitals. $€=2009$ euros.

An important limitation of the present analysis is that it does not capture the costs of achieving $8 \%$, $20 \%$ and $30 \%$ reductions in HAI incidence following surgery. However, the analysis does show the threshold at which an intervention to achieve this reduction will be cost saving. For example, if an infection control strategy resulting in an $8 \%$ reduction in HAI could be introduced in public hospitals at 
an annual cost of less than $€ 3400000$, healthcare providers would have reduced expenditure. While including the costs of interventions to achieve reductions in HAI following surgery was beyond the scope of the present analysis, the potential for significant cost savings as a result of interventions that reduce HAI incidence following surgery is worthy of further investigation.

The risk of SSI is dependent on the type and virulence of the infecting bacteria, and the immunological status of the host. Patients' characteristics and comorbidities play a key role in determining the likelihood of SSI. Factors increasing the susceptibility of patients to SSI include advanced age, poor nutritional status, diabetes, smoking, obesity, infection remote to the surgical site and lengthy preoperative hospitalization. Due to the increased resource use and cost of hospital care for patients experiencing a SSI, infection control strategies to reduce the incidence are important, particularly in patients at the highest risk.

While it is acknowledged that not all SSIs can be prevented, evidence suggests that the current level of incidence can be reduced [1-3]. The majority of SSIs occur at superficial sites around foreign material left in the wound [16]. One potential avenue for improving infection control is in the choice of sutures, which are known to provide a focal point for bacterial colonization, act as a vehicle to transport bacteria into the wound and afford a repository for bacteria in the suture knot. Use of triclosan-coated sutures reduces SSIs by preventing bacterial colonization of the wound around the suture, due to the presence of an antimicrobial. Triclosan is a broad-spectrum antimicrobial agent, possessing mostly antibacterial, but also some antifungal and antiviral properties. Use of triclosan-coated sutures has been shown to reduce SSI incidence by $8 \%(7 \%$ vs. $15 \%)$ in a comparison with conventional sutures [15]. Examination of this benefit in the present scenario analysis suggests that this reduction in SSI incidence may have a substantial impact on both the clinical and economic burden, reducing the number of hospital stays, length of stay and cost of care by as much as $€ 4588519$ per year. Further economic evaluation of the benefit of introduction of infection control interventions such as triclosan antibacterial sutures in the French setting may be warranted based on these observations.

The World Health Organization and the Centre for Disease Control and Prevention have issued guidelines detailing pre-, peri- and post-operative infection control actions that can be used to reduce the incidence of SSIs $[17,18]$. Preoperatively patients should be treated to resolve infections remote from the surgical site and appropriate disinfection of the skin at the surgical site should take place, with shaving only performed if absolutely necessary $[17,18]$. If the patient is considered at high risk of SSI, a prophylactic dose of an appropriate antimicrobial should be administered, ideally intravenously, at a time to establish a bactericidal concentration at the operational site $[17,18]$. Surgical team members should follow good practice guidelines for hand washing and preoperative aseptic procedures $[17,18]$. During the surgical procedure, surgical team members should use surgical masks, caps, gowns, gloves and drapes and replace these items when they become soiled $[17,18]$. The operating theatre should be cleaned using a hospital-approved disinfectant and good practice used to maintain sterility of surgical instruments [17, 18]. Air within the operating theatre should be changed at least 15 times per hour, with three of these being with fresh air, and filtering should take place using an appropriate filter [17, 18]. In the post-operative period, sterile dressing should be used and sterile techniques should be adhered to during dressing changes [17, 18]. Patients should undergo post-operative surveillance, including post-discharge if required, with any SSI assessed and reported appropriately [17, 18]. SSI rates should then be conveyed to surgical team members $[17,18]$. All of these steps offer opportunities to reduce SSI incidence. Some estimates have suggested that up to $55 \%$ of SSIs can be prevented [5]. The present study used conservative estimates of an overall reduction in incidence of $20-30 \%$ in SSIs. The analyses suggest that substantial reductions in healthcare expenditure could occur if SSI incidence is reduced. With greater decreases in SSI incidence larger cost savings can be expected, as the required number of hospital days of care will be reduced beyond the levels estimated in this study.

The present study has quantified the substantial economic burden that SSIs following a limited selection of procedures place on the healthcare system in France to be $€ 57892715$ per year. However, our analysis was conservative and the total burden is expected to be greater, both clinically and economically. New infection control interventions which reduce SSI incidence have the potential to lessen the clinical and economic burden, providing valuable cost savings to healthcare providers and should be the subject of future health economic evaluations. 


\section{DECLARATION OF INTEREST}

Ludovic Lamarsalle is an employee of HEVA, and Barnaby Hunt and William Valentine are employees of Ossian Health Economics and Communications. These institutions received unrestricted funding from Ethicon, EMEA to perform the present study. Marion Schauf and Karine Szwarcensztein are employees of Johnson and Johnson.

\section{REFERENCES}

1. European Centre for Disease Prevention and Control. Annual epidemiological report on Communicable diseases in Europe 2008. Report on the state of communicable diseases in the EU and EEA/EFTA countries.

2. European Academies Science Advisory Council. Healthcare-associated infections: the view from EASAC. The Royal Society, London. April 2009. (http://www.easac. eu/fileadmin/PDF_s/reports_statements/Healthcareassociated.pdf). Accessed 21 January 2013.

3. Leaper DJ, et al. Surgical site infections - a European perspective of incidence and economic burden. International Wound Journal 2004; 1: 247-273.

4. Astagneau P, et al. Reducing surgical site infection incidence through a network: results from the French ISO-RAISIN surveillance system. Journal of Hospital Infection 2009; 72: 127-134.

5. Daniel F, L'Hériteau F. Surveillance of surgical site infections, France, 1999 to 2006. Saint-Maurice (Fra): Institut de veille sanitaire. October 2008. (http://www. invs.sante.fr/publications/2008/iso_raisin/iso_raisin_ rapport.pdf). Accessed 21 January 2013.

6. Carlet $\mathbf{J}$, et al. French national program for prevention of healthcare-associated infections and antimicrobial resistance, 1992-2008: positive trends, but perseverance needed. Infection Control and Hospital Epidemiology 2009; 30: 737-745.

7. Couris CM, et al. Nine-year downward trends in surgical site infection rate in southeast France (1995-2003). Journal of Hospital Infection 2007; 67: 127-134.

8. Rioux C, Grandbastien B, Astagneau P. Impact of a sixyear control programme on surgical site infections in
France: results of the INCISO surveillance. Journal of Hospital Infection 2007; 66: 217-223.

9. Umscheid CA, et al. Estimating the proportion of healthcare-associated infections that are reasonably preventable and the related mortality and costs. Infection Control and Hospital Epidemiology 2011; 32: 101-114.

10. Réseau d'alerte, d'investigation et de surveillance des infections nosocomiales (Raisin). Surveillance of surgical site infections in France 2007. Saint-Maurice (Fra): Institut de veille sanitaire. December 2009 (http:// www.invs.sante.fr/publications/2009/iso_raisin/iso_raisin_ 2007.pdf). Accessed 21 January 2013.

11. Defez C, et al. Additional direct medical costs of nosocomial infections: an estimation from a cohort of patients in a French university hospital. Journal of Hospital Infection 2008; 68: 130-136.

12. Code de la santé publique. Article L6113-7 (http://www. legifrance.gouv.fr/affichCodeArticle.do?cidTexte=LEGI TEXT000006072665\&idArticle=LEGIARTI000006690 710). Accessed 7 May 2012.

13. Code de la santé publique. Article L6113-8 (http://www. legifrance.gouv.fr/affichCodeArticle.do?cidTexte=LEGI TEXT000006072665\&idArticle=LEGIARTI000006690 711). Accessed 7 May 2012.

14. College des Economistes de la Sante (CES). Methodological guide for economic evaluation of healthcare strategies (http://www.ispor.org/peguidelines/ source/PE\%20Guide_2003.pdf). Accessed 18 June 2012.

15. Gala I, El-Hindawy K. Impact of using triclosanantibacterial sutures on incidence of surgical site infection. American Journal of Surgery 2011; 202; 133 138.

16. Katz S, Izhar M, Mirelman D. Bacterial adherence to surgical sutures: a possible factor in suture induced infection. Annals of Surgery 1981; 194: 35-41.

17. World Health Organization. WHO guidelines for safe surgery. Safe surgery saves lives. 2009 (http://whqlib doc.who.int/publications/2009/9789241598552_eng.pdf). Accessed 21 January 2013.

18. Mangram AJ, et al. Guideline for prevention of surgical site infection, 1999. Centers for Disease Control and Prevention (CDC) Hospital Infection Control Practices Advisory Committee. American Journal of Infection Control 1999; 27: 97-132. 